\title{
Application of artificial neural networks to improve power transfer capability through OLTC
}

\author{
A. Abu-Siada ${ }^{1}$, S. Islam ${ }^{1}$ and E.A. Mohamed $^{2}$ \\ ${ }^{1 *}$ Department of Electrical and Computer Engineering, Curtin University of Technology, Perth, AUSTRALIA \\ ${ }^{2}$ Department of Electrical Power Engineering, Ain Shams University, Cairo, EGYPT \\ *Corresponding Author: e-mail: a.abusiada@curtin.edu.au, Tel +61-8-92667287, Fax.+61-8-92662584
}

\begin{abstract}
On load tap changing (OLTC) transformer has become a vital link in modern power systems. It acts to maintain the load bus voltage within its permissible limits despite any load changes. This paper discusses the effect of different static loads namely; constant power $(\mathrm{CP})$, constant current $(\mathrm{CI})$ and constant impedance $(\mathrm{CZ})$ on the maximum power transfer limit from the generation to the load centre through the OLTC branch and in turn on the static stability margin of power systems. Then the paper introduces a novel approach for the on-line determination of the OLTC settings using artificial neural network (ANN) technique in order to improve the power transfer capability of transmission systems. The proposed approach is tested on a sixbus IEEE system. Numerical results show that the setting of OLTC transformer in terms of the load model has a major effect on the maximum power transfer in power systems and the proposed ANN technique is very accurate and reliable. The adaptive settings of OLTC improve the power transfer capability according to the system operating condition.
\end{abstract}

Keywords: OLTC, Static Load, Voltage Stability, ANN.

\section{Introduction}

Modern power systems are being stressed with the continuous growth of load requirements. Power system operator should ensure the quality and reliability of supply to the loads by maintaining the load bus voltages within their permissible limits. The power transfer from generators to load centers affects load bus voltages. In addition to restoring the load, OLTC also extend the power transfer ability to the load center (Zhu et al., 2000). It is well known that the operation of OLTC has a significant influence on voltage stability. Most literature has concentrated on the contribution of OLTC to voltage stability (Tylor 1994, Afzalian et al. 2008). The power transfer capability is measured by the margin from a base case operating point to the operation-limiting boundary, measured along the load growth trajectory. The static load models have an impact on the power transfer capability from generating station to the load center and thus on the static stability margin of power systems (Abu-Siada et al. 2008, Feng et al. 2004). The paper considers first the effect of different static load models namely; constant power (CP), constant current (CI) and constant impedance (CZ) load models on the power transfer limits to the load centre. Then the paper presents a novel approach for evaluating the on-line optimal settings of OLTC transformer that corresponds to the maximum power transfer to the load and hence to improve the static stability limits using artificial neural network (ANN).

\section{Effect of OLTC Setting on Power Transfer}

Assume the simple power system shown in Figure 1. The load power is supplied from an infinite bus via OLTC. The load flow equation at load bus is given by:

$$
\frac{n E-V_{L}}{j n^{2} X_{T}}=\frac{P-j Q}{V_{L}^{*}}+\frac{V_{L}}{-j X_{c}}
$$


where $E=E+j 0$ is the emf of the equivalent voltage source, $V_{L}=V_{r}+j V_{i}$ is the load bus voltage, $X_{T}=X_{\text {eq }}+X_{t r}$ is the equivalent reactance of power system $\&$ transformer, $\mathrm{P}$ and $\mathrm{Q}$ are the load active and reactive power and $X_{c}$ is the reactance of the shunt capacitor compensated load.

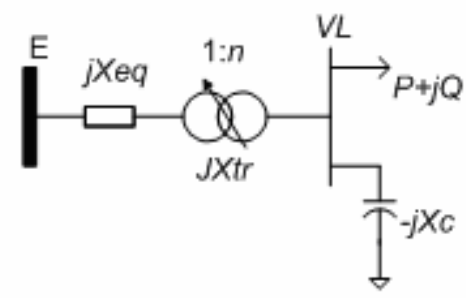

Figure. 1 Simplified power system

2.1 Constant Power (CP) Load: For constant Power load;

$P=c_{p} \quad$ and $\quad Q=c_{q}$

Let $\frac{Q}{P}=\frac{c_{p}}{C_{q}}=K$

Equation (1) can be re-written as below:

$$
-j \frac{E V_{r}}{n X_{T}}-\frac{E V_{i}}{n X_{T}}+j\left(V_{r}^{2}+V_{i}^{2}\right) \frac{X_{c}-n^{2} X_{T}}{n^{2} X_{T} X_{c}}=P-j K P
$$

Equating real parts in both sides,

$$
V_{i}=-\frac{n X_{T}}{E} P
$$

Equating imaginary parts in both sides and substituting for $V_{i}$ from (3),

Solving for $P$,

$$
\frac{n^{2} X_{T}^{2}}{E^{2}} P^{2}+\frac{n^{2} K X_{T} X_{C}}{X_{C}-n^{2} X_{T}} P+\left(V_{r}^{2}-\frac{n X_{c} E}{X_{c}-n^{2} X_{T}} V_{r}\right)=0
$$

$$
P=\frac{K X_{E} E^{2}}{2 X_{T}\left(X_{c}-n^{2} X_{T}\right)}+\sqrt{\left(\frac{K X_{C} E^{2}}{2 X_{T}\left(X_{c}-n^{2} X_{T}\right)}\right)^{2}-\left(\frac{E}{n X_{T}}\right)^{2}\left(V_{r}^{2}-\frac{n X_{C} E}{X_{c}-n^{2} X_{T}} V_{r}\right)}
$$

This solution is subject to:

$$
\begin{aligned}
& \left(\frac{K X_{C} E^{2}}{2 X_{T}\left(X_{c}-n^{2} X_{T}\right)}\right)^{2}-\left(\frac{E}{n X_{T}}\right)^{2}\left(V_{r}^{2}-\frac{n X_{c} E}{X_{c}-n^{2} X_{T}} V_{r}\right) \succ 0 \\
& \text { and } \\
& n \neq \sqrt{\frac{X_{c}}{X_{T}}}
\end{aligned}
$$

From equation (6), one can conclude that there is a limit to the power transfer to the load depends on the degree of compensation, OLTC setting and load bus voltage. Figure 2 shows the effect of OLTC tap ratio on the maximum power transfer for compensated and uncompensated load $\left(\mathrm{X}_{\mathrm{c}}=10 \mathrm{pu}\right.$. and $\mathrm{X}_{\mathrm{c}}=\infty$ respectively). For both cases the maximum power transfer limit is increased by increasing the tap ratio. Once the optimal power is reached $(0.5 \mathrm{pu}$. in case of uncompensated load and $0.56 \mathrm{pu}$. in case of compensated load) the power slightly decreases with the increase of tap ratio. It should be noted that for the compensated load, the power is dramatically increased when the resonant case is reached $\left(n=\sqrt{\frac{X_{c}}{X_{T}}}=4.472\right.$ in this case).

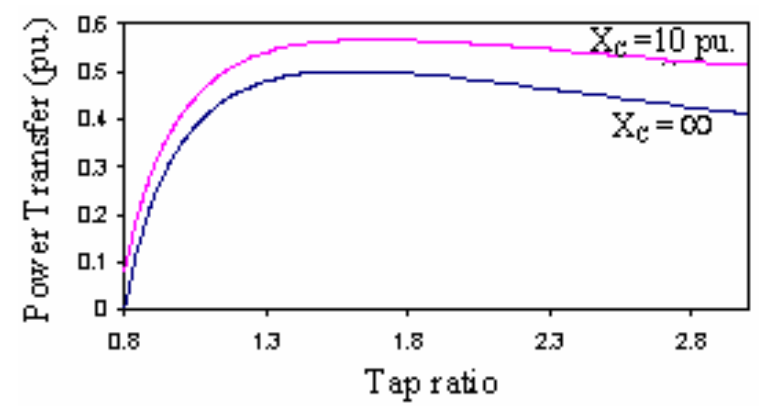

Figure 2. Effect of OLTC on power transfer to the $\mathrm{CP}$ load $\left(\mathrm{K}=0.75, \mathrm{X}_{\mathrm{T}}=0.5 \mathrm{pu}\right.$., $\mathrm{V}_{\mathrm{r}}=0.8 \mathrm{pu}$.)

Rearranging equation (4) and solving for $V_{r}$, 


$$
V_{r}=\frac{n X_{c} E}{2\left(X_{c}-n^{2} X_{T}\right)} \pm \sqrt{\left(\frac{n X_{c} E}{2\left(X_{c}-n^{2} X_{T}\right)}\right)^{2}-n^{2} X_{T} P\left(\frac{K X_{c}}{X_{c}-n^{2} X_{T}}+\frac{X_{T}}{E^{2}} P\right)}
$$

Figure 3 shows the PV curve for the uncompensated load for different tap ratios. The figure shows that the maximum power limit is constant and equal $0.5 \mathrm{pu}$. in all cases.

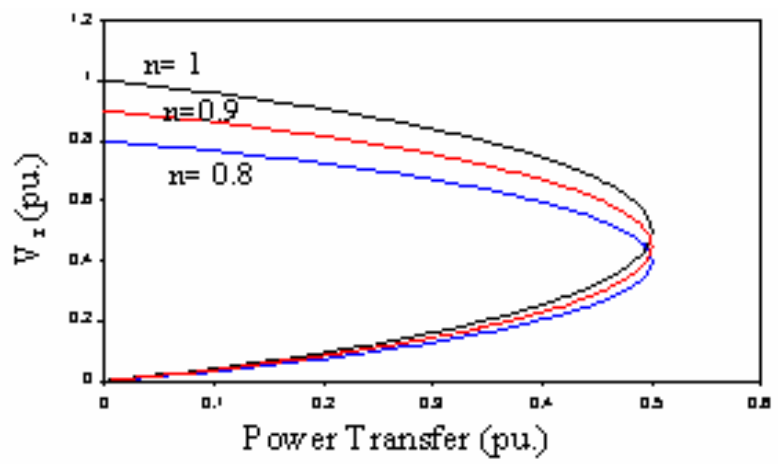

Figure 3. $\mathrm{P}-\mathrm{V}$ curve at different tap ratios $\left(X_{c}=\infty\right)$

The PV curves in Figures 4 and 5 show that the maximum power transfer limit to a compensated load can be increased by either increasing the tap ratio of OLTC or by increasing the degree of compensation. The power increase is attributed to the fact that the OLTC tap settings allow the match between the network impedance and the reflected compensated load impedance.

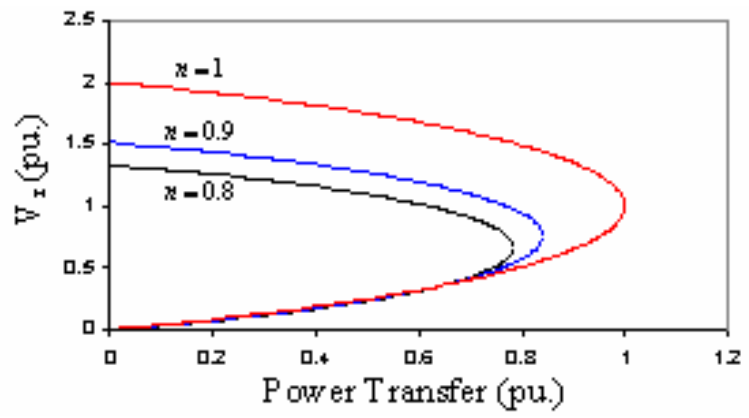

Figure 4. $\mathrm{P}-\mathrm{V}$ curve at different tap ratios $\left(X_{c}=1 \mathrm{pu}\right)$

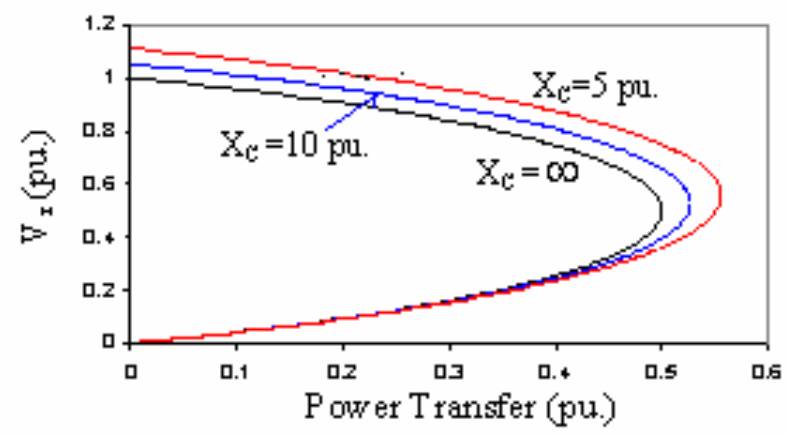

Figure 5. $\mathrm{P}-\mathrm{V}$ curve at different load compensation $(\mathrm{n}=1)$

2.2 Constant Current (CI) Load: For constant current load;

$P=c_{p}\left|V_{L}\right|, \quad Q=c_{q}\left|V_{L}\right| \quad \frac{Q}{P}=K$

Then equation (1) can be re-written as:

$$
-j \frac{E V_{r}}{n X_{T}}-\frac{E V_{i}}{n X_{T}}+j\left(V_{r}^{2}+V_{i}^{2}\right) \frac{X_{c}-n^{2} X_{T}}{n^{2} X_{T} X_{c}}=c_{p}\left|V_{L}\right|(1-j K)
$$

Equating real parts in both sides,

$$
\begin{aligned}
-\frac{E V_{i}}{n X_{T}}=c_{p}\left|V_{L}\right| \\
\Rightarrow E^{2} V_{i}^{2}=\left(n X_{T} c_{p}\right)^{2}\left(V_{r}^{2}+V_{i}^{2}\right) \\
\Rightarrow V_{i}= \pm \frac{n X_{T} c_{p}}{\sqrt{E^{2}-\left(n X_{T} c_{p}\right)^{2}}} V_{r}
\end{aligned}
$$


Equating imaginary parts and substituting for $V_{i}$

$$
\begin{gathered}
\Rightarrow V_{r}=\frac{E^{2}-\left(n X_{T} c_{p}\right)^{2}}{E\left(X_{c}-n^{2} X_{T}\right)} n X_{c}-\frac{n^{2} X_{T} X_{c} K c_{p}}{E\left(X_{c}-n^{2} X_{T}\right)} \sqrt{E^{2}-\left(n X_{T} c_{p}\right) 2} \\
\left|V_{L}\right|^{2}=V_{r}^{2}+V_{i}^{2}=V_{r}^{2}\left(1+\frac{\left(n X_{T} c_{p}\right)^{2}}{E^{2}-\left(n X_{T} c_{p}\right)^{2}}\right) \\
\Rightarrow\left|V_{L}\right|=\frac{E V_{r}}{\sqrt{E^{2}-\left(n X_{T} c_{p}\right)^{2}}} \\
P=c_{p}\left|V_{L}\right|=\frac{n c_{p} X_{c}}{X_{c}-n^{2} X_{T}} \sqrt{E^{2}-\left(n X_{T} c_{p}\right)^{2}}-\frac{n^{2} X_{c} X_{T} c_{p}^{2} K}{X_{c}-n^{2} X_{T}}
\end{gathered}
$$

This solution is subject to:

$$
\begin{aligned}
& E^{2}-\left(n X_{T} c_{p}\right)^{2} \succ 0 \\
& \Rightarrow n \prec\left|\frac{E}{X_{T} c_{p}}\right| \\
& \text { and }
\end{aligned}
$$$$
n \neq \sqrt{\frac{X_{c}}{X_{T}}}
$$

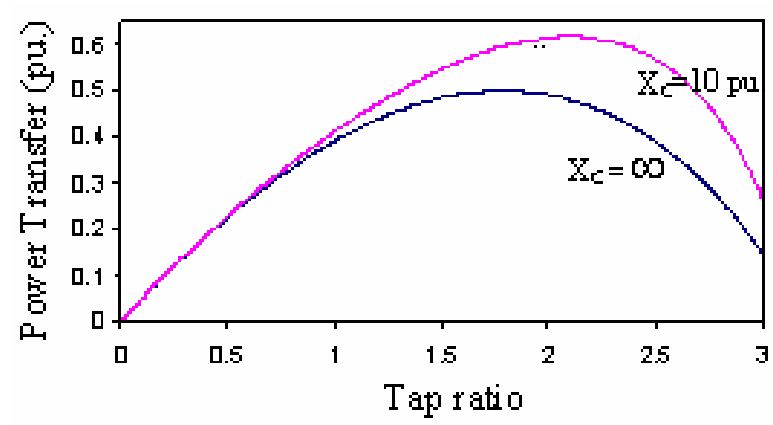

Figure 6. Effect of OLTC on power transfer to the CI load

Figure 6 shows the effect of OLTC tap ratio on the power transfer limit to constant current load. The maximum power transfer limit is increasing with the increase of the tap ratio. When the maximum limit is reached $(0.5 \mathrm{pu}$. in case of uncompensated load and $0.62 \mathrm{pu}$. in case of compensated load), the power is decreasing with the increase of tap ratio. The shunt capacitor increases the power transfer limit and shifts the optimal setting of OLTC to a higher value.

2.3 Constant Impedance (CZ) Load: For constant impedance load;

$$
P=c_{p}\left|V_{L}\right|^{2} \quad Q=c_{q}\left|V_{L}\right|^{2} \quad \frac{Q}{P}=K
$$

Then equation (1) can be re-written as:

$$
-j \frac{E V_{r}}{n X_{T}}-\frac{E V_{i}}{n X_{T}}+j\left(V_{r}^{2}+V_{i}^{2}\right) \frac{X_{c}-n^{2} X_{T}}{n^{2} X_{T} X_{c}}=P(1-j K)
$$

Equating the real parts in both sides,

$$
V_{i}=-\frac{n X_{T} P}{E}
$$

Equating imaginary parts,

$$
\begin{gathered}
V_{r}=\frac{n X_{T}}{E c_{p}}\left(K c_{p}+\frac{X_{c}-n^{2} X_{T}}{n^{2} X_{T} X_{c}}\right) P \\
\left|V_{L}\right|^{2}=V_{r}^{2}+V_{i}^{2}=\left(\frac{n X_{T}}{E c_{p}}\right)^{2}\left(K c_{p}+\frac{X_{c}-n^{2} X_{T}}{n^{2} X_{T} X_{c}}\right)^{2} P^{2}+\left(\frac{n X_{T}}{E}\right)^{2} P^{2}=\frac{P}{c_{p}} \Rightarrow P=\frac{1 / c_{p}}{\left(\frac{X_{c}-n^{2} X_{T}}{n c_{p} X_{c} E}+\frac{K n X_{T}}{E}\right)^{2}+\left(\frac{n X_{T}}{E}\right)^{2}}
\end{gathered}
$$

Figure 7 shows the effect of OLTC tap ratio on the power transfer limit to constant impedance load. Again, the power is increasing with the increase of OLTC tap ratio till the optimal power is reached then the power is decreasing with the increase of tap ratio. The optimal power in case of uncompensated load $\left(\mathrm{X}_{\mathrm{c}}=\infty\right)$ is $0.5 \mathrm{pu}$. corresponding to 1.72 tap ratio. However, the maximum power for a compensated load $\left(\mathrm{X}_{\mathrm{c}}=10 \mathrm{pu}\right.$.) is $0.62 \mathrm{pu}$. corresponding to 2.1 tap ratio. It should be noted that in all load models (CP, CI and CZ) the power transfer limit is increased by increasing the degree of compensation i.e. decreasing the value of $X_{c}$. When the load power cannot be met with the increasing compensation degree, the power can be increased by increasing the OLTC tap ratio. 


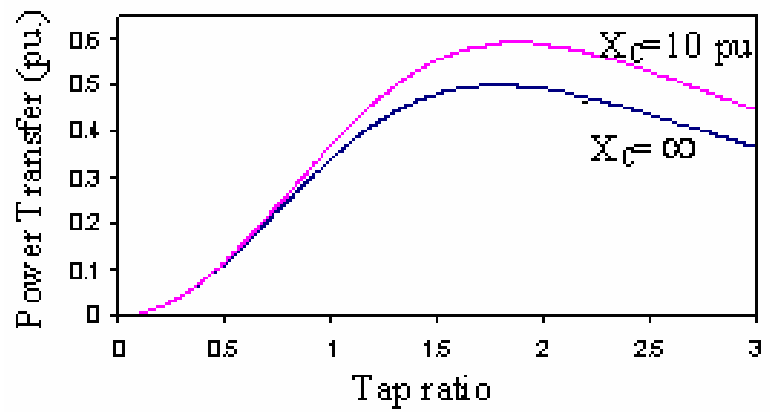

Figure 7. Effect of OLTC on power transfer to the CZ load

\section{Digital Simulation}

Figure 8 shows a one-line diagram of the IEEE 6-bus test system. The system consists of 6-nodes, 7 lines, two OLTC transformers, two generators and four loads (Tamura et al. 1993). The two OLTCs are varied one at a time, during the calculation of the maximum power transfer to the load centers.

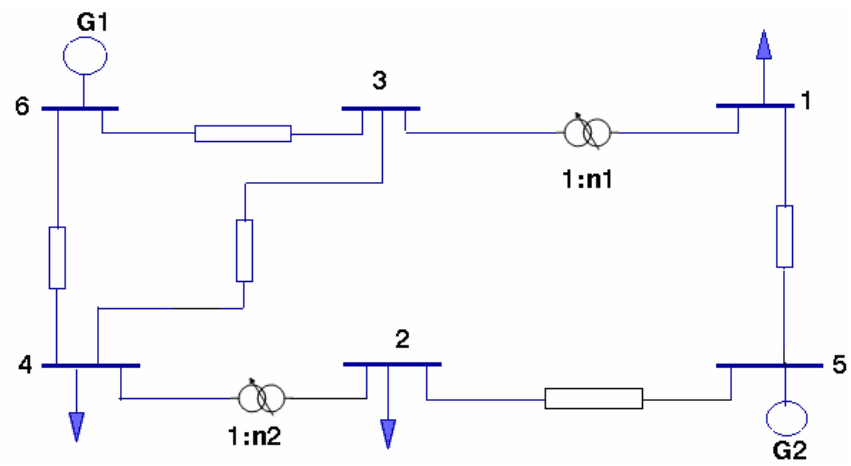

Figure 8. One line diagram of the system under study

The results obtained using the conventional methodology cover a wide range of operating conditions. A sample of the simulation results is shown in Figures 9-14. These results are presented to explore the effect of both OLTC settings and the load model on the maximum power transfer. Figures 9-11 show the relation between the power transfer to the three load buses $(1,2 \&$ 4) and the transformer tap ratio $\mathrm{n}$ under loading condition $\mathrm{P}_{\mathrm{L}}=\mathrm{Q}_{\mathrm{L}}=0.35 \mathrm{pu} .(\mathrm{pf}=0.707 \mathrm{lag})$, for the three different load models $(\mathrm{CP}, \mathrm{CI} \& \mathrm{CZ})$. From these figures, it can be seen that the optimum value of $\mathrm{n}$ and the corresponding maximum power transfer to the loads are different for the three load models. Figures 12-14 present similar results at another loading condition $\mathrm{P}_{\mathrm{L}}=0.8 \mathrm{pu}$. and $\mathrm{Q}_{\mathrm{L}}=0.13 \mathrm{pu} .(\mathrm{pf}=0.987 \mathrm{lag})$. It can be seen from these figures that the maximum power transfer limit is higher at this operating condition than the previous case and the OLTC setting $\mathrm{n}_{1}$ has a strong effect on the load at bus \#1 while the OLTC setting $\mathrm{n}_{2}$ has a stronger impact on the load at bus \#2. On the other hand, the OLTC setting $n_{2}$ has a unique correlation and effect on the load at bus \#4. These figures prove that the power transfer limit is affected by the OLTC setting for all load models.

Also, Results show that before the reverse points are reached, the upward of OLTC operation increases the maximum power transfer to the load centre. Also these results give an indication that the maximum point of power transfer and thus the levels of these powers are different for different load models. It must be noted here that, in the constant impedance (CZ) load model, the nonlinear load behavior is very sensitive to any system variation near to the static stability limit. That can be depicted from the sharp peaks indicated on Figures 10 and 14. In case of constant power (CP) load model, the load power is constant however, the power transfer to the load bus through the OLTC branch is maximized and the other shares through other branches are varied. 


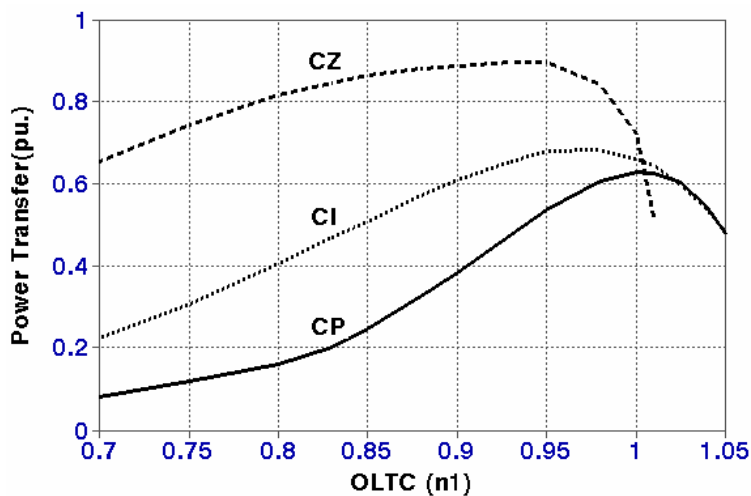

Figure 9. Effect of OLTC (n1) on Power transfer to load 1

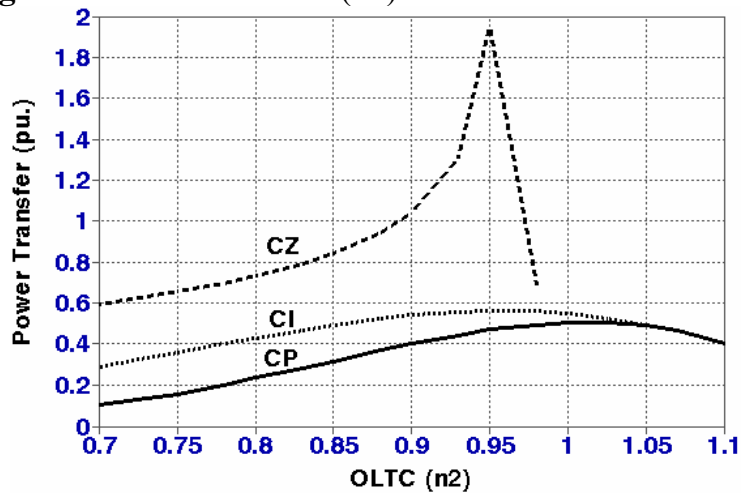

Figure 10. Effect of OLTC (n2) on Power transfer to load 2

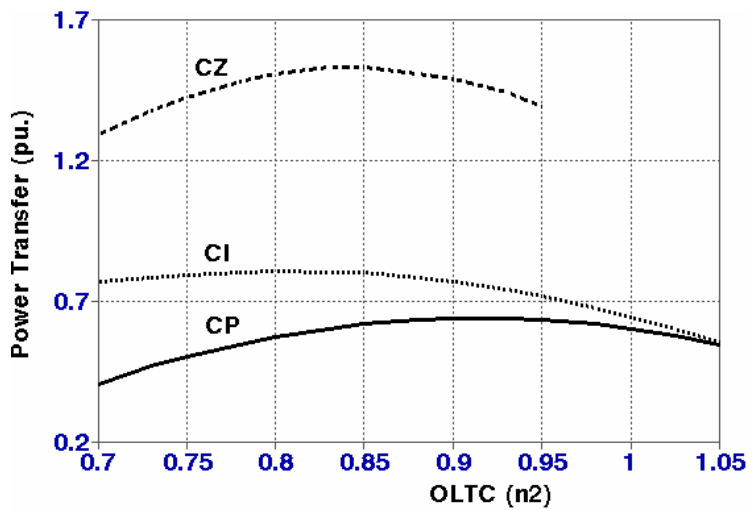

Figure 11. Effect of OLTC (n2) on Power transfer to load 3

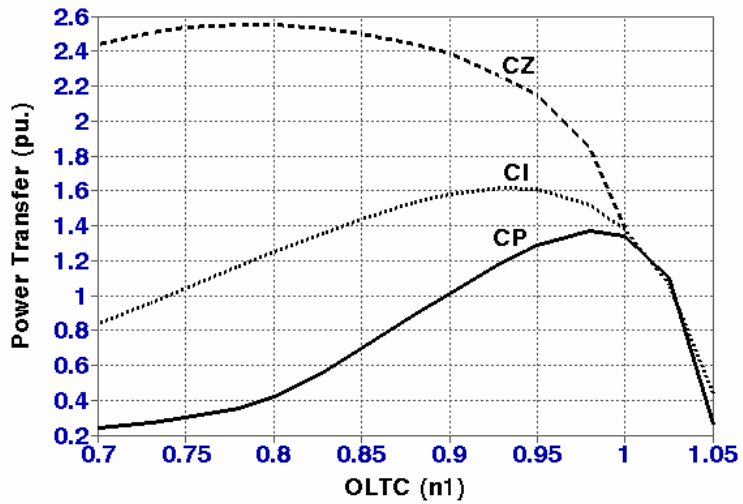

Figure 12. Effect of OLTC (n1) on Power transfer to load 1 


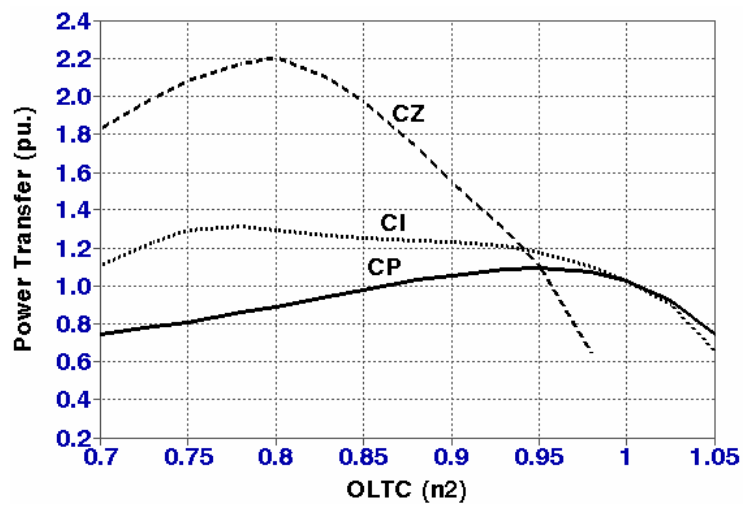

Figure 13. Effect of OLTC (n2) on Power transfer to load 2

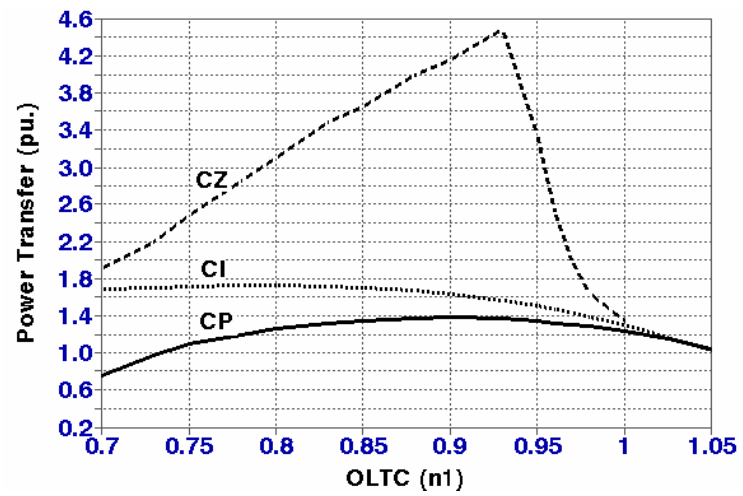

Figure 14. Effect of OLTC (n1) on Power transfer to load 3

\section{Determination of OLTC Setting using ANN}

Owing to the fast development in computing systems, application of intelligent systems such as artificial neural network (ANN) and fuzzy logic have paid a great attention in power system applications (Abu-Siada et al. 2009, Nor et al. 2003). Fuzzy logic needs a prior experience about the system to enable designing fuzzy logic rules based on the input output behaviors. ANN is selected in this paper because of its capability of learning a tremendous variety pattern mapping relationships without having prior knowledge of a mathematical function. ANN is able to handle complex non-linear problems and it overcomes the complex tedious calculation problems. The enhancement of power transfer and voltage stability can be achieved in real-time using the proposed method without any additional cost involved for installing capacitor banks and the related switches (El-Keib et al. 1999). The developed ANN model can be implemented using the currently available neural chips. The main drawback of ANN is the extensive training data required to ensure the reliability of the network.

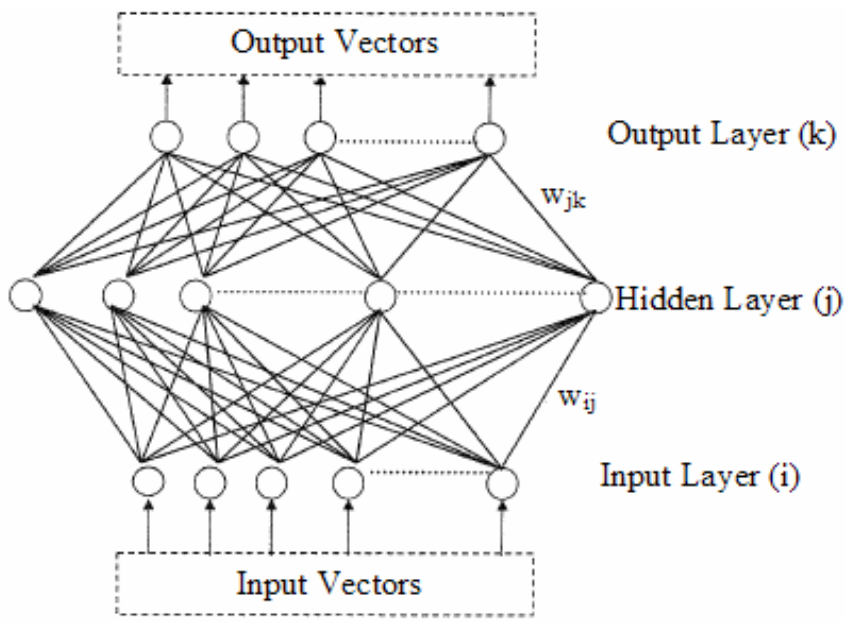

Figure 15. Typical ANN architecture model 
3.1 Topology of the ANN: The proposed ANN scheme uses a multi-layer feed-forward ANN which consists of an input layer, a hidden layer and an output layer as shown in Figure 15 (El-Sharkawi 1991, Kashem et al. 2001).

3.1.1 Input layer: Appropriate selection of input variables is the key to the success of the ANN application. Usually heuristic knowledge is required in choosing the appropriate variables. The power transfer from generation to the load centre is mainly concerned with the transformer OLTC settings. The optimal setting of the OLTC is affected by the load level. Therefore, these loading conditions are chosen as inputs to the ANN. These inputs are the load active and reactive power in addition to the generation active and reactive power at each bus in the system.

3.1.2 Hidden layer: The computational power of the ANN increases with the addition of hidden layers. There are no general guidelines to determine the number of hidden layers and number of neurons per layer. Many applications have proved that ANN with single hidden layer has sufficient capability of capturing complicated relations between input and output variables. In this paper, one hidden layer with five neurons was found satisfactory for estimating the optimal transformer OLTC settings.

3.1.3 Output layer: Determination of the output layer is quite forward. Two output neurons were used for setting the OLTC of the two transformers. The sigmoidal transfer functions have been used for all the neurons as they are suitable for any nonlinear mapping of input-output combinations because they have noise immunity for low inputs, normal outputs for middle range inputs and saturation for large inputs. Appropriate scaling of the input and output variables were carried out in the $(0,1)$ range.

3.2 Training Scenario: The scenario of the training process was started by initiating the ANN topology; i.e. the number of input nodes, the number of hidden layers, the number of neurons in different hidden layers, the number of neurons in the output layer, the type of hidden and output activation functions, and the number of presentation cycles (epochs). It must be noted, that, by adjusting the number of hidden layers and the number of simulated neurons within each layer, the performance of an ANN can be either enhanced or degraded. There are no general guidelines for a priori knowledge of which ANN architecture would perform the best for a given application. The researchers have experimented with different architectures to find out the most suitable configuration. The results obtained from the digital simulation of the system in Figure 8 were used in training and testing the proposed ANN. Back-propagation algorithm was used to train the proposed ANN using 100 training patterns with a learning rate of 0.96. The Neural Network toolbox in MATLAB is used to implement the proposed ANN. The network weights and biases initialized using random values. During training, the weights and biases are adjusted to minimize the error between the network outputs and the targets. It has been found from the simulation results that the OLTC settings and the corresponding maximum power transfer to load centers are varying with the load type. Therefore, different ANNNs have been trained for different load models.

3.3 Testing Scenario: For validating the ANN performance the scenario of the testing process is started once the training process is completed and a set of new input variables which were not used for training the ANN model are applied to the designed ANN. The proposed method has been applied to the system shown in Figure 8 and the ANN results are compared with the simulation results. The obtained results for this scenario are recorded in Tables 1,2 and 3.

\section{Results and Discussions}

The three load models under consideration are tested on different operating conditions. The transformers turns ratios are varied one at a time. The results in Table 1 have been obtained for the constant power (CP) load model. The table shows that the maximum testing absolute errors are: $5.06 \%\left(\mathrm{n}_{1}\right) \& 5.623 \%\left(\mathrm{n}_{2}\right)$. Similarly, Tables $2 \& 3$ show these errors for the constant current $(\mathrm{CI})$ and the constant impedance (CZ) load models, respectively. The maximum errors obtained in this case are: $6.0 \%\left(\mathrm{n}_{1}\right), 3.94 \%$ $\left(\mathrm{n}_{2}\right)$ and 3.66\% $\left(\mathrm{n}_{1}\right), 3.49 \%\left(\mathrm{n}_{2}\right)$, respectively. Also tables present the average and the standard deviations for the three different load models. These deviations are: 1.092/1.731 $\left(\mathrm{n}_{1}\right), 1.762 / 2.215\left(\mathrm{n}_{2}\right)$ for CP load; 1.499/2.375 $\left(\mathrm{n}_{1}\right), 1.275 / 1.636\left(\mathrm{n}_{2}\right)$ for CI model; and 1.66/1.474 $\left(\mathrm{n}_{1}\right), 0.825 / 1.19\left(\mathrm{n}_{2}\right)$ for $\mathrm{CZ}$ model. From these results, it can be seen that the CP load and the CI load models have nearly the same error level. While, the CZ load model has the less error level. The ANN is efficient for the prediction of the optimal value of transformer turns ratio settings corresponding to the maximum power transfer to the load centre.

\section{Conclusions}

An efficient method for the on line prediction of OLTC transformer settings giving maximum power transfer to the load centre is analysed. The proposed technique has been tested on the IEEE Six-bus power system. Numerical results show that the operation of OLTC transformer has a major effect on the maximum power transfer and thus on the static stability margin. Static load models such as constant power, constant current and constant impedance have a great effect not only on the maximum power transfer but also on the optimal settings of transformer OLTCs. The Artificial neural network (ANN) proved to be an efficient tool for the prediction of the optimum value of OLTC transformer settings corresponding to the maximum power transfer. The developed ANN model can be implemented using the currently available neural chips. 
Table 1. Results of ANN in case of constant power (CP) load model

Training Scenario

Testing Scenario

\begin{tabular}{|c|c|c|c|c|c|c|c|c|c|c|c|}
\hline \multicolumn{2}{|c|}{$\begin{array}{c}\text { Predicted } \\
\text { Values }\end{array}$} & \multicolumn{2}{c|}{$\begin{array}{c}\text { Desired } \\
\text { Values }\end{array}$} & \multicolumn{2}{c|}{ \%Error } & \multicolumn{2}{c|}{$\begin{array}{c}\text { Predicted } \\
\text { Values }\end{array}$} & \multicolumn{2}{c|}{$\begin{array}{c}\text { Desired } \\
\text { Values }\end{array}$} & \multicolumn{2}{c|}{$\%$ Error } \\
\hline $\mathrm{n}_{1}$ & $\mathrm{n}_{2}$ & $\mathrm{n}_{1}$ & $\mathrm{n}_{2}$ & $\mathrm{n}_{1}$ & $\mathrm{n}_{2}$ & $\mathrm{n}_{1}$ & $\mathrm{n}_{2}$ & $\mathrm{n}_{1}$ & $\mathrm{n}_{2}$ & $\mathrm{n}_{1}$ & $\mathrm{n}_{2}$ \\
\hline .9983 & .9943 & 1 & 1 & -.17 & -.57 & .9983 & .993 & .98 & 1 & 1.86 & -.77 \\
.9985 & .9952 & 1 & 1.02 & -.15 & -2.48 & .9982 & .992 & 1 & .98 & -.18 & 1.143 \\
.997 & .8988 & 1 & .9 & -.30 & -.133 & .9965 & .852 & 1 & .85 & -.35 & .897 \\
.9985 & .9933 & 1 & 1 & -.15 & -.670 & .9984 & .991 & .98 & 1 & 1.88 & -.9 \\
.9981 & .9852 & 1 & 1 & -.19 & -1.48 & .9976 & .966 & 1 & .95 & -.24 & 1.684 \\
.9975 & .9202 & 1 & .93 & -.25 & -1.05 & .9974 & .917 & 1 & .9 & -.26 & 1.888 \\
.9985 & .994 & 1 & 1 & -.15 & -.6 & .9984 & .993 & .99 & 1 & .899 & -.670 \\
.9983 & .9909 & 1 & 1 & -.17 & -.91 & .9981 & .989 & 1 & .98 & -.19 & -.908 \\
.9975 & .9339 & 1 & .93 & -.25 & .419 & .9971 & .897 & 1 & .88 & -.29 & 2.125 \\
.9983 & .9898 & .98 & 1 & 1.867 & -1.02 & .9981 & .986 & .95 & 1 & 5.06 & -1.54 \\
.9972 & .9324 & 1 & .93 & -.28 & .258 & .997 & .919 & 1 & .9 & -.3 & 1.544 \\
.9972 & .8942 & 1 & .9 & -.28 & -.644 & .9968 & .843 & 1 & .85 & -.32 & -.318 \\
.9982 & .9914 & .98 & 1 & 1.857 & -.86 & .9981 & .982 & .96 & 1 & 3.99 & -1.08 \\
.998 & .9839 & 1 & .95 & -.2 & 3.58 & .9978 & .983 & 1 & .93 & -.22 & 5.623 \\
.9962 & .8411 & 1 & .85 & -.38 & 1.07 & .9963 & .873 & 1 & .83 & -.37 & 5.337 \\
\hline \multicolumn{3}{c|}{ Average deviation } & .443 & 1.047 & & & & & 1.092 & 1.762 \\
& Standard deviation & & .7368 & 1.361 & & & & & 1.71 & 2.215 \\
\hline
\end{tabular}

Table 2. Results of ANN in case of constant Impedance (CI) load model

Training Scenario

Testing Scenario

\begin{tabular}{|c|c|c|c|c|c|c|c|c|c|c|c||}
\hline \multicolumn{2}{|c|}{$\begin{array}{c}\text { Predicted } \\
\text { Values }\end{array}$} & \multicolumn{2}{c|}{$\begin{array}{c}\text { Desired } \\
\text { Values }\end{array}$} & \multicolumn{2}{c|}{$\%$ Error } & \multicolumn{2}{c|}{$\begin{array}{c}\text { Predicted } \\
\text { Values }\end{array}$} & \multicolumn{2}{c|}{$\begin{array}{c}\text { Desired } \\
\text { Values }\end{array}$} & \multicolumn{2}{c|}{$\%$ Error } \\
\hline $\mathrm{n}_{1}$ & $\mathrm{n}_{2}$ & $\mathrm{n}_{1}$ & $\mathrm{n}_{2}$ & $\mathrm{n}_{1}$ & $\mathrm{n}_{2}$ & $\mathrm{n}_{1}$ & $\mathrm{n}_{2}$ & $\mathrm{n}_{1}$ & $\mathrm{n}_{2}$ & $\mathrm{n}_{1}$ & $\mathrm{n}_{2}$ \\
\hline .9703 & .9915 & .98 & 1 & -.989 & -.85 & .9456 & .9929 & .95 & 1 & -.463 & -.71 \\
.9843 & .9406 & 1 & .95 & -1.57 & -.989 & .9862 & .9275 & 1 & .93 & -1.38 & -.269 \\
.9927 & .8067 & 1 & .80 & -.73 & .838 & .9935 & .7767 & 1 & .78 & -.65 & -.33 \\
.9489 & .9920 & .95 & 1 & -.116 & -.80 & .9453 & .9929 & .93 & 1 & 1.645 & -.71 \\
.9910 & .9440 & 1 & .93 & -.90 & 1.51 & .9924 & .9252 & 1 & .9 & -.76 & 2.8 \\
.9931 & .8606 & 1 & .85 & -.69 & 1.24 & .9939 & .8383 & 1 & .83 & -.61 & 1 \\
.9483 & .9922 & .95 & 1 & -.179 & -.78 & .9466 & .9926 & .94 & 1 & -.702 & -.74 \\
.9878 & .9458 & 1 & .95 & -1.22 & -.442 & .9893 & .9342 & 1 & .93 & -1.07 & .45 \\
.9931 & .8328 & 1 & .83 & -.69 & .337 & .9943 & .7923 & 1 & .8 & -.57 & -.963 \\
.9581 & .9876 & .93 & 1 & 3.02 & -1.24 & .9531 & .9897 & .9 & 1 & 5.9 & -1.03 \\
.9952 & .7850 & .78 & 1 & -.48 & .641 & .9958 & .7319 & 1 & .75 & -.42 & -2.41 \\
.9947 & .8032 & 1 & .78 & -.53 & .40 & .9953 & .7753 & 1 & .78 & -.47 & -.602 \\
.9579 & .9876 & .93 & 1 & 3.0 & -1.24 &, 9540 & .9899 & .9 & 1 & 6.0 & -1.01 \\
.9849 & .9171 & 1 & .90 & -1.51 & 1.9 & .9869 & .8990 & 1 & .88 & -1.31 & 2.159 \\
.9929 & .7577 & 1 & .75 & -.71 & 1.027 & .9947 & .6724 & 1 & .70 & -.53 & -3.94 \\
\hline \multicolumn{3}{|c|}{ Average deviation } & 1.225 & .9489 & & & & & 1.499 & 1.275 \\
\multicolumn{3}{c|}{ Standard deviation } & & 1.563 & 1.067 & & & & & 2.375 & 1.636 \\
\hline
\end{tabular}


Table 3. Results of ANN in case of constant current (CZ) load model

\begin{tabular}{|c|c|c|c|c|c|c|c|c|c|c|c|}
\hline & & \multicolumn{4}{|c|}{ Training Scenario } & \multicolumn{4}{|c|}{ Testing Scenario } & & \\
\hline \multicolumn{2}{|c|}{$\begin{array}{l}\text { Predicted } \\
\text { Values }\end{array}$} & \multicolumn{2}{|c|}{$\begin{array}{l}\text { Desired } \\
\text { Values }\end{array}$} & \multicolumn{2}{|c|}{$\%$ Error } & \multicolumn{2}{|c|}{$\begin{array}{l}\text { Predicted } \\
\text { Values }\end{array}$} & \multicolumn{2}{|c|}{$\begin{array}{l}\text { Desired } \\
\text { Values }\end{array}$} & \multicolumn{2}{|c|}{ \% Error } \\
\hline $\mathrm{n}_{1}$ & $\mathrm{n}_{2}$ & $\mathrm{n}_{1}$ & $\mathrm{n}_{2}$ & $\mathrm{n}_{1}$ & $\mathrm{n}_{2}$ & $\mathrm{n}_{1}$ & $\mathrm{n}_{2}$ & $\mathrm{n}_{1}$ & $\mathrm{n}_{2}$ & $\mathrm{n}_{1}$ & $\mathrm{n}_{2}$ \\
\hline .9444 & .9956 & .95 & 1 & -.59 & -.44 & .9437 & .9948 & .93 & 1 & 1.47 & -.52 \\
\hline .9955 & .9494 & 1 & .95 & -.45 & -.06 & 9959 & .9251 & 1 & 93 & -.41 & -.527 \\
\hline .9965 & .8510 & 1 & .85 & -.35 & .118 & .9965 & .8280 & 1 & .83 & -.35 & -.24 \\
\hline .9872 & .9856 & .98 & 1 & -.735 & -1.44 & .964 & 9919 & .93 & 1 & 3.66 & -.810 \\
\hline .9980 & .7494 & 1 & .75 & -.2 & -.08 & .9978 & .7437 & 1 & .73 & -.22 & 1.877 \\
\hline .9982 & .785 & 1 & .78 & -.18 & .641 & .9981 & .7498 & 1 & .75 & -.19 & -.27 \\
\hline .9750 & .9912 & .97 & 1 & .515 & -.88 & .9695 & .9910 & .95 & 1 & 2.053 & -.90 \\
\hline .9975 & .8291 & 1 &. .83 & -.25 & -.108 & .9975 & .8018 & 1 & .8 & -.25 & .18 \\
\hline .9978 & .7706 & 1 & .78 & -.22 & -.94 & .9977 & .7407 & 1 & .75 & -1.56 & -1.24 \\
\hline .7996 & .9984 & .8 & 1 & -.05 & -.16 & .9844 & .9651 & .79 & 1 & 1.823 & $-3-49$ \\
\hline 9979 & .7996 & 1 & .8 & -.21 & -.05 & .9978 & .7883 & 1 & .78 & -.22 & 1.064 \\
\hline .9972 & .9343 & 1 & .93 & -.28 & .46 & .9974 & .9052 & 1 & .90 & -.26 & .578 \\
\hline .8527 & .9977 & .85 & 1 & .318 & -.23 & .8226 & .9978 & .8 & 1 & 2.83 & -.22 \\
\hline .9963 & .8299 & 1 & .83 & -.37 & .012 & .9965 & .7965 & 1 & .80 & -.35 & -.438 \\
\hline .9951 & .8023 & 1 & .8 & -.49 & .288 & .9954 & .7821 & 1 & .78 & -.35 & .269 \\
\hline \multirow{2}{*}{\multicolumn{4}{|c|}{$\begin{array}{l}\text { Average deviation } \\
\text { Standard deviation }\end{array}$}} & .349 & .394 & & & & & 1.66 & .825 \\
\hline & & & & .3836 & .547 & & & & & 1.474 & 1.19 \\
\hline
\end{tabular}

\section{References}

Abu-Siada A., S. Islam and E. A. Mohamed, 2008. Adaptive Setting of OLTC to Improve Power Transfer Capability of Power Systems, CMD'08, Beijing, China, March.

Abu-Siada A., S. Islam and S. Lai, 2008. A Novel Application of Gene Expression Programming in Transformer Diagnostics, AUPEC'08, Sydney, December.

Abu-Siada A., S. Islam and S. Lai, 2009. Remnant Life Estimation of Power Transformer using Oil UV-Vis Spectral Response,

IEEE PES Power Systems Conference \& Exhibition (PSCE), USA, March.

Afzalian A., A. Saadatpoor and W. Wonham, 2008. Systematic supervisory solutions for under-load tap-changing transformers, Control Engineering Practice, Vol. 16, pp1035-1054.

Dilon T. S., 1991. Artificial Neural Network Applications to Symbolic Methods, Journal of Electrical Power and Energy System, Vol. 13, No. 2, pp. 66-72.

El-Keib A. and X. Ma, 1999. Application of Artificial Neural Networks in Voltage Stability Assessment, IEEE Transaction on Power Systems, Vol. 10, Nov.

EL-Sharkawi M. A., R, J. Marks and Siri Weerasooriya, 1991. Neural Networks and Their Application to Power Engineering, control and Dynamics serial Academic Press.

Feng Dong et al, 2004. Impact of Load Tab Changing Transformers on Power Transfer Capability, Electric Power Components and Systems, Vol. 32, pp. 1331-1346.

Gwang Won Kim and Kwang Y. Lee, 2005. Coordination Control of ULTC Transformer and STATCOM Based on an Artificial Neural Network, IEEE Transactions on Power Systems, Vol. 20, No. 2, pp 580-586.

Kashem M. A., V. Ganapathy and G. B. Jasmon, 2001. On-line Network Reconfiguration for Enhancement of Voltage Stability in

Distribution Systems using Artificial Neural Networks, Electrical Power Components and Systems, Vol. 29, pp. 361-373.

Lai S., A. Abu-Siada, S. Islam. 2008. Correlation between UV-Vis Spectral Response and Furan Measurement of Transformer Oil, CMD’08, Beijing, China, March.

Les M.Hajagos, and Behnam Danai, 1998. Laboratory Measurements and Models of Modern Loads and Their Effects on voltage Stability Studies, IEEE Transaction on Power Systems, vol. 6, No.2 May, pp.584-591.

Nor Haidar et al., 2003. Application of ANN to Determine the OLTC in Minimizing the Real Power Losses in Power System, National Power and Energy Conference Proceddings, Malaysia.

Qin Zhou et.al., 1994. Application Of Artificial Neural Networks In Power System Security And Vulnerability Assessment, IEEE Transaction on Power Systems, Vol.9, No.1, February, pp. 525-532.

Qiu J. and S.M.Shahidelhpour; 1987. A New Approach For Minimizing Power Losses and Improving Voltage Profile”. IEEE Transaction on Power Systems, Vol. PWRS-2, No.2, May, pp. 287-295.

Tamura, Y.Mori, H.Iwamoto,S., 1993. Relationship between Voltage Instability and Multiple Load Flow Solutions in Electric Power Systems, IEEE Transaction on Power Apparatus and Systems, PAS-102, No.5, pp.1115-1125.

Taylor C. W., 1994, Power System Voltage Stability, New York; McGraw-Hill, Inc.

Zhu T. X., S.K. Tso. and K.L.Lo., 2000. "An Investigation into the OLTC Effects on Voltage Collapse, IEEE Transaction on power Systems, vol.15. No.2, May, pp.515-521. 
Biographical notes:

Ahmed Abu-Siada received the B.Sc. and M.Sc. degree from Ain Shams University, Egypt and the PhD degree from Curtin University of Technology, Perth, Australia, All in Electrical Engineering. Currently, he is a lecturer in the Department of Electrical and Computer Engineering at Curtin University of Technology. His research interests include power System Stability and Control, Power Electronics, Power Quality, Condition Monitoring, Energy Technology and System Simulation. He is a member of IEEE.

Syed Islam (S'81, M, 83, SM'93) received the B.Sc., MSc, and PhD degree all in electrical power engineering in 1979, 1983, and 1988 respectively. He is currently the Chair Professor in Electrical Power Engineering and Head of Department of Electrical and Computer Engineering at Curtin University of Technology, Perth, Australia. He received the IEEE T Burke Haye's Faculty Recognition award in 2000. He has published over 140 technical papers in his area of expertise. His research interests are in Condition Monitoring of Transformers, Wind Energy Conversion, and Power Systems. He has been a keynote speaker and invited speaker at many international workshops and conferences. He is the current Vice-Chair of the Australasian Committee for Power Engineering (ACPE) and a member of the steering committee of the Australian Power Institute. He is a Fellow of the Engineers Australia, a senior member of the IEEE IAS, PES and DEIS, a Fellow of the IET and a chartered engineer in the United Kingdom. He is regular reviewer for the IEEE Trans. on Energy Conversion, Power Systems and Power Delivery. Prof. Islam is an editor of the IEEE Transaction on Sustainable Energy.

E.A. Mohamed received the B.Sc. and M.Sc. degree from Ain Shams University, Egypt and the PhD degree from the University of Manitoba, Canada, All in Electrical Engineering. Currently, he is a Professor in the Department of Electrical Engineering, Ain Shams University, Egypt His research interests include power System Stability and Control, Power Quality, Application of AI to power systems and System Simulation.

Received August 2009

Accepted March 2010

Final acceptance in revised form March 2010 